Research Paper:

\title{
The Effect of Aromatherapy by Inhalation and Massage on Radiotherapy-induced Fatigue in Patients With Cancer
}

\author{
Mojgan Moradi $^{*}$ (D), Alice Khachian', Farshad Amini Behbahani² ${ }^{1}$, Kiarash Saatchi ${ }^{3}$, Hamid Haghani ${ }^{4}$ (i) \\ 1. Department of Medical-Surgical Nursing, School of Nursing and Midwifery, Iran University of Medical Sciences. Tehran, Iran \\ 2. School of Persian Medicine, Iran University of Medical Sciences, Tehran, Iran. \\ 3. Board Member of Acupuncturist, the Board of Iranian Scientific Acupuncture Association of Iran, Tehran, Iran. \\ 4. Department of Statistics, School of Health, Iran University of Medical Sciences, Tehran, Iran.
}

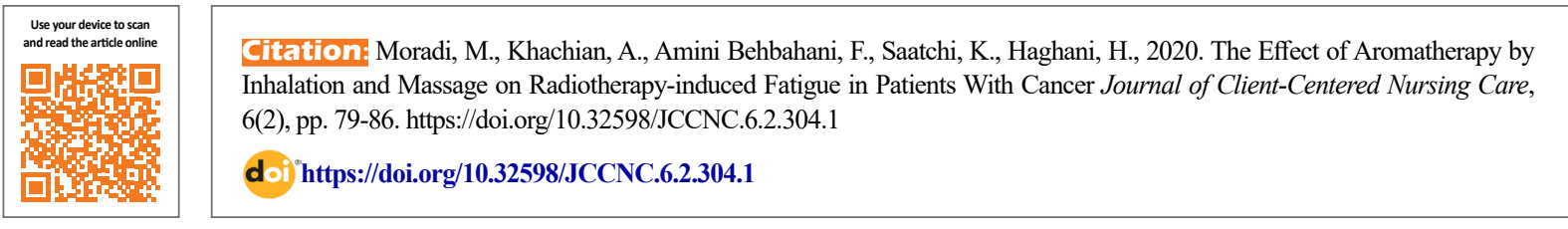

\section{(1) (3)}

Article info:

Received: 04 Oct 2019

Accepted: 15 Mar 2020

Published: 01 May 2020
Keywords:

Aromatherapy, Inhalation, Massage, Fatigue,

Radiotherapy, Cancer

\section{A B S T RA C T}

Background: Fatigue is one of the most prevalent and debilitating complications of cancer and its treatments. Patients undergoing radiotherapy experience some degrees of fatigue. Complementary medicine methods have reduced the complications of treatments in many disorders. Accordingly, the present study was conducted to compare the effect of aromatherapy by inhalation and massage on radiotherapy-induced fatigue in patients with cancer.

Methods: In this randomized clinical trial, 105 patients with cancer undergoing radiotherapy in the oncology ward of Firouzgar Hospital in Tehran, Iran were selected conveniently based on the inclusion criteria and were randomly assigned into three groups of inhalation aromatherapy, massage aromatherapy, and control groups. In the first group, viola and almond oil were inhaled, in the second group, the Swedish massage was performed using aromatic oil, and the control group received routine care. Fatigue was measured by the Multidimensional Fatigue Inventory (MFI) before, and at the end of the intervention. The data were analyzed by descriptive and inferential statistics (ANOVA, Paired T-tests, Fischer's exact, and Chi-square tests) using SPSS software V. 16. The significance level was considered as $\mathrm{P} \leq 0.05$.

Results: The findings showed that the three studied groups had no significant statistical difference in terms of demographic characteristics before the intervention. Fatigue score was significantly different in all three groups after both interventions $(\mathrm{P}<0 / 001)$, which indicated a decrease in fatigue in the two test groups. However, according to Scheffe post hoc test, massage aromatherapy was more effective in reducing fatigue resulting from radiotherapy.

Conclusion: The results of this study showed that massage aromatherapy was more effective in reducing radiotherapy-induced fatigue in patients with cancer. It is recommended that future studies recruit another group that receives the only massage.

\section{* Corresponding Author:}

Mojgan Moradi, MSc.

Address: Department of Medical-Surgical Nursing, School of Nursing and Midwifery, Iran University of Medical Sciences. Tehran, Iran.

Tel: +98(935) 7731172

E-mail: moradi.moj@iums.ac.ir 


\section{Highlights}

- Fatigue is considered as one of the most prevalent complications of cancer and its treatments.

- The complementary medicine methods with low cost and low risk can be used in patients with cancer.

- An aromatherapy massage is more effective than aromatherapy by inhalation in reducing fatigue resulting from radiotherapy in patients with cancer.

\section{Plain Language Summary}

Fatigue is one of the most prevalent complications of cancer and its treatments. The current study assessed the effect of aromatherapy by inhalation and massage on radiotherapy-induced fatigue in patients with cancer in Tehran, Iran. Cancer complications affect all aspects of life and disrupt the normal course of family life due to its debilitating nature. Fatigue management includes pharmaceutical and non-pharmaceutical interventions. Aromatherapy by massage and inhalation can be used as a cost-effective, safe, and ordinary complementary therapy to reduce fatigue in patients with cancer; however, aromatherapy by massage is more effective.

\section{Introduction}

atigue is exhaustion and disability in performing activities; however, there is no comprehensive definition of fatigue and its pathophysiological perception. Although fatigue is not an illness it is one of the most prevalent symptoms that appear in primary care (Jordan et al. 2017; Saremi \& Fallah 2013). Fatigue was derived from a Latin term of "fatiguer" which means "breakdown". It is a major complaint among the general public and patients and is associated with reduced energy and loss of physical power. Following nursing research on fatigue, the North American Nursing Diagnosis Association (NANDA) accepted fatigue as a nursing diagnosis and defined it in 1988 as a self-diagnostic state that is characterized by weakness and reduced capacity to perform intellectual and physical activities.

Tired /exhausted people do not have the energy they used to have and perform fewer activities and make more effort for the least everyday activities; hence, this issue affects their quality of life and self-confidence (Sajadi, A. \& Abotalebi 2012; Taylor \& Johnson 2010). Many factors, including physical causes, medical conditions, mental health problems, and a special lifestyle cause fatigue. Generally, suffering from some diseases, such as depression, multiple sclerosis, and cancer, or some medical treatments, like chemotherapy and radiotherapy are considered as the known and main reasons for fatigue (Alizadeh Fard 2011; Arrol 2014).
Cancer, with 14.1 million cases in the world, has been known as one of the most chronic, non-contagious, and prevalent states in many countries. Cancer-related mortality was 8.2 million deaths in 2012 and is increasing (Washington, \& Leaver 2015). Almost 60\% of patients with cancer undergo radiotherapy during their treatment process. Radiotherapy is one of the most important branches of medical physics, and it is said to treat the disease using penetrating rays, such as X-ray, alpha, beta, and gamma that are radiated either from the device or from drugs that contain tagged materials (WHO 2018; Washington, \& Leaver 2015).

Fatigue has been considered as one of the chronic complications of radiotherapy. During radiotherapy, patients with cancer experience a lot of physical and mental fatigue. Radiotherapy-induced Fatigue (RIF) accumulates gradually throughout the course of treatment and continues for months after the end of radiotherapy. RIF is an early and long-term problem of the treatment with radiation that starts from the second week of radiotherapy and reaches its peak in the sixth week. The prevalence of fatigue in patients undergoing radiotherapy has been reported to be $90-80 \%$, and it is a combination of weakness, lack of energy, boredom, lack of concentration, and exhaustion, and sometimes, leads to discontinuation of treatment (Hsiao et al. 2016; Janaki et al. 2010).

Considering the low efficiency of existing drugs to relieve fatigue and the many problems and complications resulting from pharmacological therapy, it seems reasonable to use non-pharmacological methods that can reduce fatigue. In recent years, complementary medi- 
cine methods have been widely considered and the acceptance of these treatments is expanding (Bach et al. 2016; Myhill 2014).

Complementary medicine is a kind of therapy that acts in conjunction with standard care and can be performed simultaneously with common treatments carried out by health care providers, including nurses. Complementary medicine emphasizes that therapy should be "holistic". One of the methods of complementary medicine is aromatherapy, in which herbal oils and extracts with different properties are used for specific therapeutic purposes. Aromatherapy is performed more by inhalation and massage (Shamsi Khani \& Saeedi 2016).

In aromatherapy, by inhalation, the aromatic oil stimulates the olfactory receptor cells and is then transmitted to the limbic system, where it is perceived (Bastani et al. 2017). With the rhythmic, influential pressure during the massage method, the herbal oils are quickly absorbed through the skin, enter the bloodstream and remain their herbal relaxing, analgesic, and antispasmodic effects (Adarvishi et al. 2016; Marzouk, Marzouk, El-Nemer, \& Baraka 2013).

Currently, there are more than 80 types of massage, of which the Effleurage massage is very relaxing, simple, and light. Effleurage movements are able to increase blood circulation and lymph flow, induction of relaxation, improvement of muscle aches, fatigue, sleep problems, and muscle contractions and is very suitable for the patients with cancer (Field 2016; Gensic, Smith \& Labarbera 2017).

Almond-Violet oil affects mild burns and reduces fatigue by improving sleep. Since patients undergoing radiotherapy experience some degrees of skin burn in addition to fatigue, this oil seems to be very appropriate for radiotherapy-induced burns (Nafis-ebne-Avaz 2008; Feyzabadi et al. 2014).

Viola odorata is used in Iranian traditional medicine for the treatment of cancer, migraine, cough, inflammation, fever, anxiety, high blood pressure, kidney and liver disorders, and bacterial infections. It is also used as a sedative. The effect of Viola flower extract on the prevention and contributory treatment of cancer, especially gastrointestinal cancers, and surgery-induced metastasis of tumors has been examined in various studies (Alipanah et al. 2017).

The extract of V. odorata contains alkaloid, glycoside, saponin, methyl salicylate, and vitamin C. The combined oil of the Viola and Almond is an aromatic oil and has been widely used in Iranian traditional and Islamic medicine. It is prepared by the combination of the sweet Almond oil and violet flower and is the best oil, which has been used for the treatment of many diseases because of its sedative and anxiolytic effects, relieving effects on itching and inflammation of the skin, relieving muscle and joint pains, , reducing nervous pressures, and strengthening hair and eyebrows, and also for physical exhaustion somnolence (Mozaffarian 2016).

Considering the high prevalence of fatigue and a high number of studies on cancer-related fatigue and radiotherapy-induced fatigue, as well as disregarding these complications despite their occurrence in $90 \%$ of patients with cancer and the imperfect effect of a pharmaceutical therapy to control patients' fatigue, this study was conducted to examine the effect of aromatherapy by inhalation and massage on radiotherapy-induced fatigue in the patients with cancer.

\section{Materials and Methods}

\section{Design, Setting, and Sample}

This randomized clinical trial was conducted in the oncology ward of Firouzgar Hospital in Tehran, Iran from November 2017 to April 2018. A total of 105 cancer patients undergoing radiotherapy were selected by convenient sampling based on the inclusion criteria and then were randomly assigned into three groups of inhalation aromatherapy $(n=35)$, massage aromatherapy $(n=35)$, and control group $(n=35)$. The sample size was estimated to be at least 32 in each group and considering 10\% attrition, 35 subjects were considered for each group.

The inclusion criteria were 2 weeks have passed since the start of radiotherapy, ability to communicate, the absence of mental disorders, having a healthy sense of smell /olfaction, the age of 18-60 years, lack of ulcer, redness, and bulge on limbs, no history of migraine, asthma, and other respiratory diseases, and having the reading and writing literacy (either by the patients or their concomitants).

\section{Measurements}

Data were collected by the Multidimensional Fatigue Inventory (MFI). MFI is a self-report instrument consisting of 20 items, which is scored based on a 5-point Likert scale from 1-5. It measures five dimensions of fatigue, including general fatigue, physical fatigue, reduced motivation, reduced activity, and mental fatigue. MFI was first developed by Smets et al. in 1996, and its validity 
and reliability have been evaluated in various demographic groups, such as cancer patients receiving radiation therapy, psychology students, and medical students. Questions 2, 5, 9, 10,13,14,16,17, and18 are reversely scored. The overall score varies between 20 and 100, and a higher score indicates more fatigue.

According to previous studies, confirmatory factor analysis shows that the questions of each dimension describe the same dimension and the questionnaire has a good internal consistency (Cronbach's alpha coefficient is 0.84) (Chandel et al. 2015; Smets et al. 2009; Ueki et al. 2014). This questionnaire has been translated into Persian and its reliability and validity have been confirmed in Iran. The alpha coefficient for general, physical, and mental fatigue was higher than 0.80 , and for reduced activity and motivation was higher than 0.65 (Khani Jazani 2012). In this study, Cronbach's alpha and test-retest methods were used to evaluate the reliability of the instrument. The questionnaire was completed by 15 patients and seven days later, they completed the questionnaire again and the reliability coefficient was found to be 0.90 . Its Cronbach's alpha was also 0.76 .

\section{Procedure}

After receiving ethical approvals, written informed consent was obtained from the subjects. Viola and almond oil was prepared from Tuba's Talaye Sabz Company. It was prepared from a mixture of sweet almond seed oil (glyceryl oleate) and viola flowers. Radiotherapy was performed every other day.
In the first group, after radiotherapy, the patients' finger was dipped in a drop of aromatic oil and placed inside their nose to inhale for three days (every other day, each time for $5 \mathrm{~min}$ ). In the second group, Effleurage massage was performed for $30 \mathrm{~min}$, with rotatory movements of the massager's thumb, using 3-5 cc of viola and almond oil in the Back-Shu Points (for three days, every other day after radiotherapy).

This area is located on the path of the paravertebral muscles. The subjects were laying on their abdomen during the procedure and massage was performed by the researcher and a researcher assistant (both had completed massage educational courses and had a relevant certificate and authorization for performing massage). The control group received routine care. MFI was completed before the intervention and immediately after the end of the third session of intervention by the three groups (due to the nature of the intervention, there was no possibility of blinding).

The data were analyzed by descriptive and inferential statistics (ANOVA, Paired T-tests, Fischer's exact, and Chi-square tests) using SPSS software version 16. It should be noted that two patients in the control group were excluded due to hospitalization, five patients in the inhalation group due to lack of cooperation or death, and two patients in the massage group due to death and hospitalization (Figure 1).

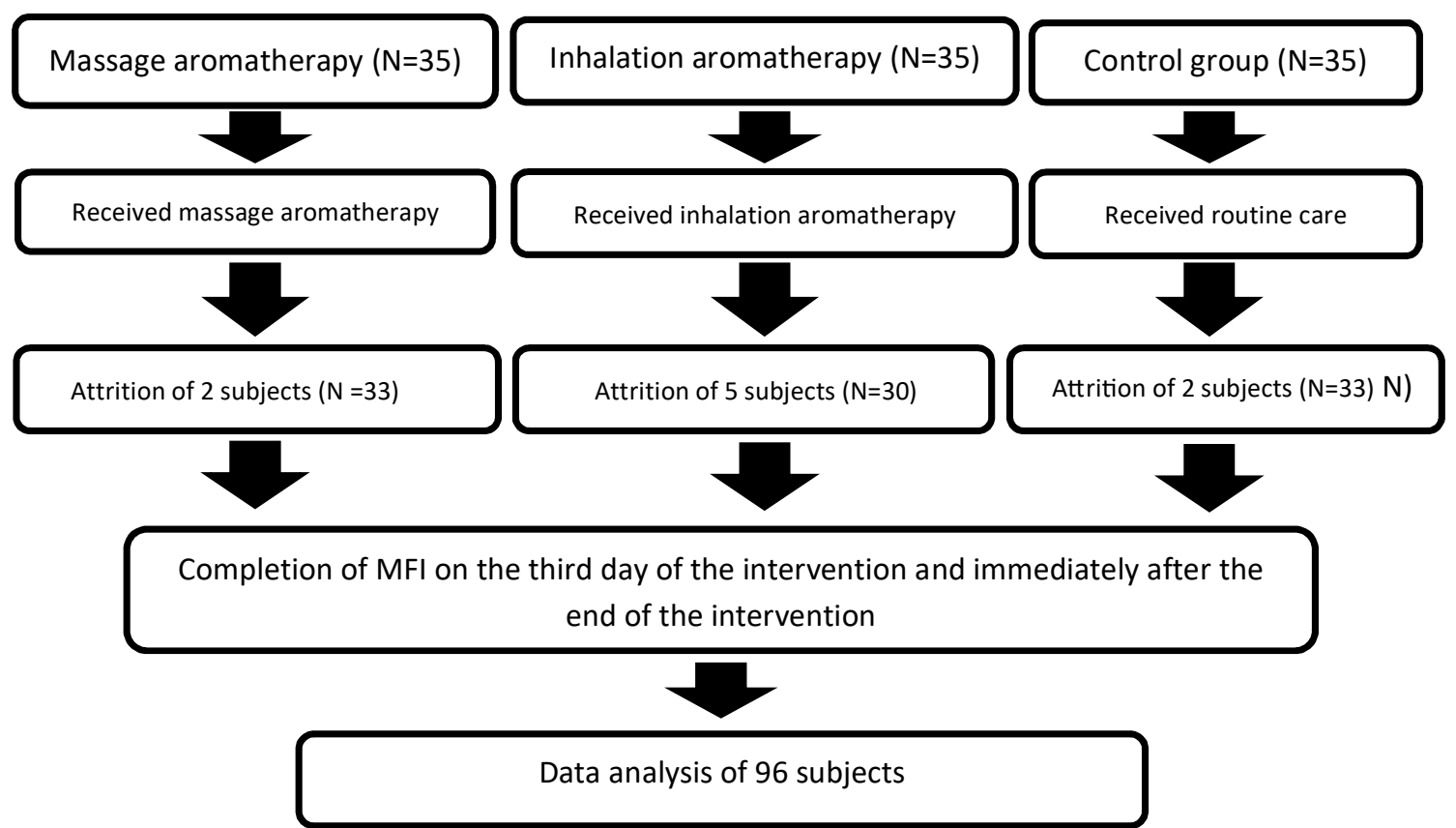

Figure 1. The procedure flowchart 
Table 1. Demographic characteristics of the studied patients $(n=96)$

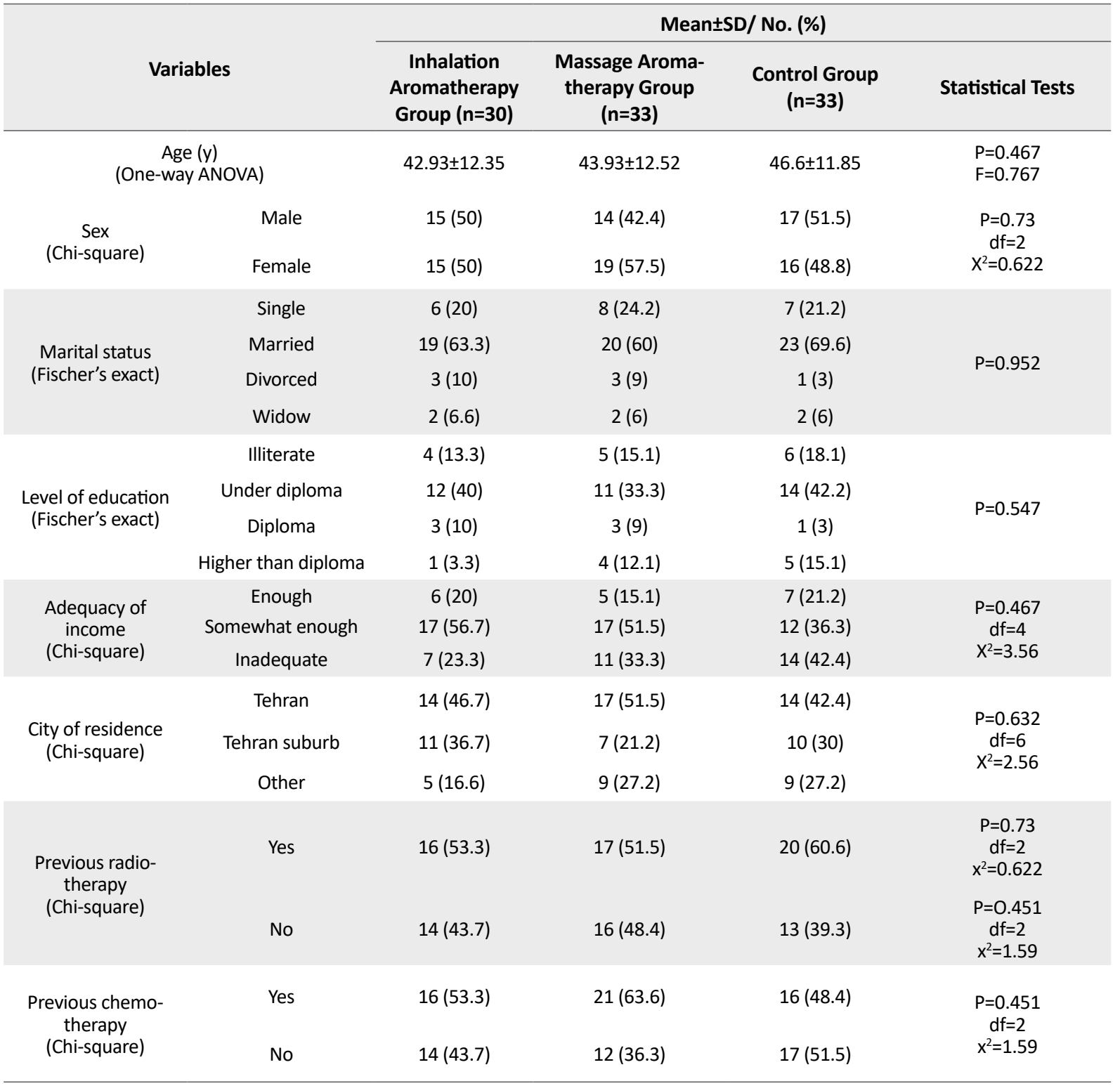

\section{Results}

There was no significant difference between the groups in terms of age, sex, marital status, educational level, income level, the place of residence, previous history of radiotherapy, and previous history of chemotherapy. Most of the subjects were over 50 years of age and married with almost enough income, under diploma education, and a history of chemotherapy and radiotherapy and lived in Tehran (52\% were female) (Table 1).

Before the intervention, the mean fatigue score in the inhalation aromatherapy, massage aromatherapy, and control groups were $65.90 \pm 14.78,67.36 \pm 11.83$, and $64.59 \pm 14.75$, respectively, which showed no significant statistical difference between the three groups (Table 2); however, it changed to $54.26 \pm 12.68,59.27 \pm 14.43$, and $69.50 \pm 14.39$, respectively, which represented a significant statistical reduction after the intervention both experimental groups $(\mathrm{P}<0.05)$ (Table 3$)$.

The results of the Scheffe post hoc test showed that the mean score of fatigue was significantly different between the control group and the inhalation group after the intervention $(\mathrm{P}<0.001)$. Also, the difference between the mean fatigue of the control group and the aromatherapy by massage group was significant $(\mathrm{P}<0.001)$. However, the difference of the mean fatigue score between the two groups of aromatherapy was not significantly different 
Table 2. Comparison of mean fatigue score in the studied patients before the intervention

\begin{tabular}{|c|c|c|c|}
\hline \multirow{2}{*}{$\begin{array}{l}\text { Group } \\
\text { Fatigue } \\
\text { Score }\end{array}$} & \multicolumn{3}{|c|}{ No. (\%) } \\
\hline & Massage Aromatherapy & Inhalation Aromatherapy & Control \\
\hline $\begin{array}{c}\text { Low Fatigue } \\
(20-40)\end{array}$ & $0(0.0)$ & $1(3.3)$ & $2(3.1)$ \\
\hline $\begin{array}{l}\text { Moderate } \\
\text { Fatigue } \\
(40-60)\end{array}$ & $11(33.7)$ & $10(39.3)$ & $11(34.4)$ \\
\hline $\begin{array}{c}\text { Severe Fatigue } \\
(60-100)\end{array}$ & $22(64.2)$ & $19(63.3)$ & $20(62.5)$ \\
\hline Total & $33(100)$ & $30(100)$ & $33(100)$ \\
\hline Mean $\pm S D$ & $11.83 \pm 67.36$ & $14.78 \pm 65.90$ & $14.75 \pm 64.59$ \\
\hline One-Way ANOVA & $F=0.327$ & & \\
\hline
\end{tabular}

( $\mathrm{P}=0.306)$; but the aromatherapy by massage was more effective in reducing radiotherapy-induced fatigue.

\section{Discussion}

In this study, the effect of aromatherapy by inhalation and massage on the radiotherapy-induced fatigue was examined in patients with cancer. According to the results, the hypothesis of the effectiveness of the aromatherapy by massage in reducing fatigue was confirmed. Based on the results, fatigue decreased in both groups of the aromatherapy intervention, but the aromatherapy by massage was more effective in reducing the fatigue of these patients. A study on assessing the effect of aromatherapy by hand massage on fatigue and sleep among North Korean hospital patients, showed that aromatherapy by massage is effective in reducing fatigue and improving the quality and quantity of sleeping (Park, Chun, \& Kwak 2016), which is consistent with our study.
The results of a clinical trial in the United States, entitled "The effect of Swedish massage on cancer-induced fatigue", showed that Swedish massage for six weeks reduced the mean fatigue score and had a significant effect on cancer-induced fatigue (Kinkead et al. 2018). A study in Turkey on the effect of aromatherapy by massage on fatigue and pain in patients with cancer also showed that the aromatherapy by massage is useful in the management of fatigue and peripheral neuropathic pain resulting from chemotherapy (Izgu, Ozdemir, \& Bugdayci Basal 2017).

In line with the results of our study, another study in Turkey on the effect of back massage on fatigue and anxiety associated with chemotherapy also indicated that after back massage in the intervention group, patients' fatigue and anxiety of the intervention group showed a significant decrease immediately and a day after massage compared with the control group (Karagozoglu \& Kahve 2013). The results of these two studies are somewhat

Table 3. Comparison of mean fatigue score in the studied patients after the intervention

\begin{tabular}{|c|c|c|c|}
\hline \multirow[t]{2}{*}{ Group } & \multicolumn{3}{|c|}{ No. (\%) } \\
\hline & Massage Aromatherapy & Inhalation Aromatherapy & Control \\
\hline $\begin{array}{l}\text { Low fatigue } \\
\qquad(20-40)\end{array}$ & $1(3)$ & $5(16.7)$ & $1(3)$ \\
\hline $\begin{array}{c}\text { Moderate } \\
\text { Fatigue }(40-60)\end{array}$ & $16(48.5)$ & $12(40)$ & $9(27.3)$ \\
\hline $\begin{array}{c}\text { severe Fatigue } \\
(60-100)\end{array}$ & $16(48.5)$ & $13(43.3)$ & $23(69.7)$ \\
\hline Total & $33(100)$ & $30(100)$ & $30(100)$ \\
\hline Mean $\pm S D$ & $11.43 \pm 59.27$ & $12.68 \pm 54.26$ & $14.39 \pm 69.50$ \\
\hline One-way ANOVA & $F=11.7$ & & \\
\hline
\end{tabular}


consistent with the results of the present study, but our research was done on patients undergoing radiotherapy.

The results of a study on assessing the effectiveness of Swedish massage with lavender oil on muscle strength of post-stroke patients in Indonesia showed that Swedish massage with lavender oil was effective in strengthening the muscles and reduced the muscle fatigue (Sari, Karim, \& Elita 2016), which is consistent with the results of our study using Effleurage massage instead of a Swedish massage. A study to compare the effect of back massage and music on fatigue in patients with chronic heart failure in Tehran showed that back massage had a greater effect on reducing fatigue (Najafi Ghezeljeh, Salehzadeh \& Rafii 2016).

The results of another study revealed that aromatherapy by massage had a positive effect on the fatigue and hemodynamic indices of elderly women with the acute coronary syndrome (Bahrami et al. 2016). The results of a study that was conducted to assess the effect of aromatherapy by massage on fatigue intensity in female patients with multiple sclerosis indicated a positive effect of this intervention (Bahraini et al. 2011). The results of all the mentioned studies are consistent with ours.

\section{Conclusion}

Aromatherapy by massage and inhalation were both effective in reducing fatigue in patients with cancer; however, aromatherapy by massage was more effective. Regarding the result of this study and most of the other related studies, it can be concluded that patients with cancer always experience some degrees of fatigue, and using non-pharmacological and low-complication methods, such as aromatherapy could be helpful in decreasing their fatigue.

Considering that a part of the effectiveness of aromatherapy massage might have been due to the effects of massage alone, it is recommended that future studies recruit another group that receives the only massage. It is suggested to compare the effects of the methods in this study with other complementary methods. Studies to examine the long-term effects of aromatherapy massage on patients with cancer are also suggested.

\section{Ethical Considerations}

\section{Compliance with ethical guidelines}

The study approved by the Ethics Committee of Iran University of Medical Sciences (IR.IUMS.FMD.
REC 1396.9411686010). This study was also registered at the Iran Registry of Clinical Trials (IRCT) (IRCT20171203037735N1). Written informed consent was obtained from all the subjects.

\section{Funding}

This article was extracted from the MSc. thesis of the first author in the Department of Medical-Surgical Nursing, School of Nursing and Midwifery, Iran University of Medical Sciences.

\section{Conflict of interest}

The authors declared no conflicts of interest.

\section{Acknowledgments}

We appreciate the financial support of the Vice Chancellor for Research of Iran University of Medical Sciences. The collaboration of the staff of Firouzgar hospital and all the patients who participated in this study is also appreciated.

\section{References}

Adarvishi, S., et al., 2016. [The effects of aromatherapy massage using peppermint oil on physiological indicators after laparoscopic cholecystectomy surgery: A control clinical trials (Persian)]. Preventive Care in Nursing \& Midwifery Journal, 6(2), pp. 24-35. http:// zums.ac.ir/nmcjournal/article-1-342-en.html

Alipanah, H., et al., 2017. [Comparing the effect of hydro-alcoholic extract of viola odorata and melatonin on tumor growth and NF-kB, TNFR1, and VCAM-1 expression rates in 4T1 breast cancer model: An in vivo study (Persian)]. Journal of Mazandaran University of Medical Sciences, 27(147), pp. 2540. http://jmums.mazums.ac.ir/article-1-9858-en.html

Alizadeh Fard, S., 2009. [Fatigue and ways to overcome it (Persian)]. Tehran: Mosallas. http://opac.nlai.ir/opac-prod/bibliographic/1570346

Arroll, M. A., et al., 2014. The delayed fatigue effect in myalgic encephalomyelitis/chronic fatigue syndrome (ME/CFS). Fatigue: Biomedicine, Health \& Behavior, 2(2), pp. 57-63. https://doi.org/10.1080/21641846.2014.892755

Bach, H. V., et al., 2016. Efficacy of ginseng supplements on fatigue and physical performance: A meta-analysis. Journal of Korean Medical Science, 31(12), pp. 1879-86. [DOI:10.3346/ jkms.2016.31.12.1879] [PMID] [PMCID]

Bahraini, S., et al., 2011. [The comparison of the effects of effleurage massage with aromatic oil and non aromatic oil on fatigue severity in women with multiple sclerosis (Persian)]. Nursing and Midwifery Urmia Journal, 9(5), pp. 327-36. http://unmf. umsu.ac.ir/article-1-604-en.html 
Bahrami, T., et al., 2016. [Effect of aromatherapy massage on fatigue and hemodynamic parameters in elderly women with acute coronary syndrome (Persian)]. Nursing and Midwifery Urmia Journal, 14(4), pp. 343-50. http:// unmf.umsu.ac.ir/article-1-2791-en.html

Bastani, F., Samady Kia, P. \& Haghani, H., 2017. The effect of inhalation aromatherapy with damask rose (rosa damascena) on the pain of elderly after knee arthroplasty. Journal of Client-Centered Nursing Care, 3(2), pp. 153-60 [DOI:10.32598/jccnc.3.2.153]

Chandel, P., et al., 2015. Validation of the Hindi version of the Multidimensional Fatigue Inventory-20 (MFI-20) in Indian cancer patients Support Care Cancer, 23(10), pp. 2957-64. [DOI:10.1007/s00520-015-2661-5] [PMID]

Feyzabadi, Z., et al., 2014. Efficacy of viola odorata in treatment of chronic insomnia. Iranian Red Crescent Medical Journal, 16(12), p. e17511. [DOI:10.5812/ircmj.17511]

Field, T., 2016. Massage therapy research review. Complementary Therapies in Clinical Practice, 24, pp. 19-31. [DOI:10.1016/j. ctcp.2016.04.005] [PMID] [PMCID]

Gensic, M. E., Smith, B. R. \& Labarbera, D. M., 2017. The effects of effleurage hand massage on anxiety and pain in patients undergoing chemotherapy. JAAPA, 30(2), pp. 36-8. [DOI:10.1097/01.JAA.0000510988.21909.2e] [PMID]

Hsiao, C. P. Daly, B. \& Saligan, L. N., 2016. The etiology and management of radiotherapy-induced fatigue. Expert Review of Quality of Life in Cancer Care, 1(4), pp. 323-8. [DOI:10.1080 /23809000.2016.1191948] [PMID] [PMCID]

Izgu, N., Ozdemir, L. \& Bugdayci Basal, F., 2019. Effect of aromatherapy massage on chemotherapy-induced peripheral neuropathic pain and fatigue in patients receiving oxaliplatin: An Open Label Quasi-Randomized Controlled Pilot Study. Cancer Nursing, 42(2), pp. 139-47. [DOI:10.1097/ NCC.0000000000000577]

Janaki, M. G., et al., 2010. Magnitude of fatigue in cancer patients receiving radiotherapy and its short term effect on quality of life. Journal of Cancer Research and Therapeutics, 6(1), pp. 226. [DOI:10.4103/0973-1482.63566] [PMID]

Jordan, B., et al., 2017. Assessment of physical fatigability and fatigue perception in myasthenia gravis. Muscle \& Nerve, 55(5), pp. 657-63. [DOI:10.1002/mus.25386] [PMID]

Karagozoglu, S. \& Kahve, E., 2013. Effects of back massage on chemotherapy-related fatigue and anxiety: Supportive care and therapeutic touch in cancer nursing. Applied Nursing Research, 26(4), pp. 210-7. [DOI:10.1016/j.apnr.2013.07.002] [PMID]

Khani Jazani, R., et al., 2012. [Different scales of fatigue in traffic policemen (Persian)]. Journal of Police Medicine, 1(1), pp. 5-14. http://teb.police.ir/teb/article-1-58-fa.html

Kinkead, B., et al., 2018. Massage therapy decreases cancer-related fatigue: Results from a randomized early phase trial. Cancer, 124(3), pp. 546-54. [DOI:10.1002/cncr.31064] [PMID] [PMCID]

Marzouk, T. M. F., El-Nemer, A. M. R. \& Baraka, H. N., 2013. The effect of aromatherapy abdominal massage on alleviating menstrual pain in nursing students: A prospective randomized cross-over study. Evidence-Based Complementary and Alternative Medicine, 2013, p. 742421. [DOI:10.1155/2013/742421] [PMID] [PMCID]
Mozaffarian, V., 2012. [Recognition of medicinal and aromatic herbs of Iran (Persian)]. Tehran: Farhang Moaser. http:// opac.nlai.ir/opac-prod/bibliographic/2985922

Myhill, S., 2014. Diagnosis and treatment of chronic fatigue syndrome: It's mitochondria, not hypochondria. London: Hammersmith Health Books. https://books.google.com/ books?id=ijfMoAEACAAJ\&dq

Nafis-ebne-Avaz., 2008. [Akbari medicine (Arzani, M. A., Persian trans.)]. Qom: Jalal-al-din. http://opac.nlai.ir/opacprod/bibliographic/2042852

Najafi Ghezeljeh, Salehzadeh, H. T., \& Rafii, F., 2016. [Comparing the effects of back massage and music on fatigue in patients with chronic heart failure (Persian)]. J Urmia Nurs Midwifery Fac 14(6), pp. 516-25. http://unmf.umsu.ac.ir/article-1-2832-en.html

Park, H., Chun, Y. \& Kwak, S., 2016. The effects of aroma hand massage on fatigue and sleeping among hospice patients. Open Journal of Nursing, 60(7), pp. 515-23. [DOI:10.4236/ojn.2016.67054]

Sajadi, A. \& Abotalebi, G., 2012. [Chronic fatigue from diagnosis to relief (Persian)]. Journal of the School of Army Nursing, 12(1), pp. 18-22. http://eprints.ajaums.ac.ir/1719/

Saremi, M. \& Fallah, M. R., 2013. [Subjective fatigue and medical errors among nurses in an educational hospital (Persian)]. Iran Occupational Health Journal, 10(4), pp. 1-8. http://ioh.iums. ac.ir/article-1-805-en.html

Sari, N., Karim, D. \& Elita, V., 2016. The effectiveness of Swedish massage with lavender oil to improve muscle strength of poststroke patients. https://www.semanticscholar.org/paper/ The-Effectiveness-Of-Swedish-Massage-With-Lavender-SariKarim/44543753985f5b83652f332fa8d3442ea5808fb5

Shamsi Khani, S. Saeedi, M., 2016. [Complementary medicine, alternative medicine and nurses' role in them (Persian)]. Tehran: Heydari. http://opac.nlai.ir/opac-prod/bibliographic/3747326

Smets, E. M. A., et al., 2009. The Multidimensional Fatigue Inventory (MFI) psychometric qualities of an instrument to assess fatigue. Journal of Psychosomatic Research, 39(3), pp. 315-25. [DOI:10.1016/0022-3999(94)00125-O]

Taylor, J. \& Johnson, M., 2010. How women manage fatigue after childbirth. Midwifery, 26(3), pp. 367-75. [DOI:10.1016/j. midw.2008.07.004] [PMID] [PMCID]

Ueki, S., et al., 2014. Effectiveness of aromatherapy in decreasing maternal anxiety for a sick child undergoing infusion in a paediatric clinic. Complementary Therapies in Medicine, 22(6), pp. 1019-26. [DOI:10.1016/j.ctim.2014.09.004] [PMID]

World Health Organization (WHO)., 2013. WHO traditional medicine strategy: 2014-2023 [Internet]. [Cited 27 September 2020]. Essential Medicines and Health Products. https:// www.who.int/medicines/publications/traditional/trm strategy14_23/en/

Washington, C. M. \& Leaver, D. T., 2015. Principles and practice of radiation therapy. Philadelphia: Elsevier Health Sciences. https:/ / books.google.com/books?id=N-h1BwAAQBAJ\&dq 